\title{
College English Education under the Perspective of Cultural Security
}

\author{
Jianxian Huang
}

Chongqing College of finance and economics, Chongqing, 402160, China

\begin{abstract}
With the popularization of network and the development of science and technology, the consciousness of globalization and internationalization receives the attention from more and more people. Under such circumstance, China's college English education is also under flourishing development. Under such historical background, we should clearly realize the consciousness of cultural security. On this basis, the author in this paper analyzes and reflects on college English education from the perspective of security, with expectations to provide valuable reference to foreign language education for college students in China.
\end{abstract}

Key words: cultural security, college English education, value orientation

With the development of globalization, the world is now developing toward such trends as globalization, networking and global village. Under such development situation, cultural security becomes more and more important, especially in the process of foreign language education in colleges and universities. Besides enhancing foreign language proficiency of students, we also need to develop foreign language education for college students under the perspective of cultural security, help college students to establish standard consciousness of cultural security, and positively seek for Sino-foreign cultural exchanges and foreign language education paths in conformity with cultural security in China.

\section{Concept of Cultural Security}

So-called cultural security refers to a kind of standard of behavior established on the basis of social system and cultural values. This moral code is a kind of intangible resource difficult to be controlled. It represents the autonomy of a country free from intervention, control and assimilation from foreign element or culture in terms of culture, spiritual life and other aspects and maintaining its ethnic and national ideology all the time with its ethnic values and modes of life. The development of a country's cultural system is an aggregation combining legality and rationality of the country's cultural existence and development based on a non-threat circumstance. Generally speaking, cultural security indicates that a country utilizes independent ideology and political institution to boycott other 
foreign ideologies and protect its people’s values, social system, political institution, national consciousness, behavioral pattern and others from free intervention, and expands the influence of its culture in the world through certain means, beneficial for protection of its national characters, national pride and cohesion.

\section{Current Situation of China's Cultural Security}

\section{Chinese culture is still in a weak situation in the world; and western culture} still in the hegemonic position.

China's reform and opening-up policy has already gone through many years. With the deepening of opening-up, the influence of Chinese culture becomes more and more profound $\mathrm{n}$ the world. However, Chinese culture is still in a weak position at present. Therefore, we should strengthen the protection of cultural security. The influence of cultural security involves many aspects of a country, such as economy and military. Moreover, a powerful cultural country must have culture with international influence and experts \& scholars in all aspects. Both cultural quality and educational status should be very high for people. According to the analysis from the perspective of historical development, Chinese culture was ever strong in the world. With the development of the reform and opening-up policy, China's comprehensive national strength also got remarkable improvement. China's culture receives the attention from more and more people in the world. Moreover, China's culture also aroused a new wave of Chinese fever in the world. However, this can not completely change the position of Chinese culture in the world. China's cultural security is still under the threat from western culture.

\section{China is in a social transformation period, with conflicts between foreign} values and local values.

With the development of market and society, China has already stepped into the transformation period: the primary stage of socialism. In this transformation period, we are confronted with many contradictions. However, these contradictions are characterized with fast change and rapid development. Under such social background, China's old and new values replace each other and coexist. A series of conflicts were formed between some foreign values and local ones, for instance, conflicts formed between economic difference existing in the social industry and obligations that must be performed during the practical work process of teachers. China is now in the transformation period: the primary stage of socialism. In this period, China is featured by the most contradictions, the fastest change and the 
rapidest development of these contradictions as well as replacement and coexistence of old and new values and conflicts between western values and local values. Such social background promotes the diversified and complex situation of China's values. Teachers need to have certain professional ethics and concern and love their students. Due to a variety of reasons, however, many teachers failed to invest their passion into the teaching industry or pay enough attention to their students, lacking the most basic professional ethics as well as lofty sentiment and elevated belief. It is very difficult for find plain of Chinese nation on many teachers. On this basis, many social contradictions were caused. At the same time, the situation of social dissatisfaction for the teaching industry was also caused. Due to many reasons, other industries regarded knowledge as a tool for benefits, lacking industrial consciousness of responsibility. For a higher level, they lack humanistic feelings.

\section{Strategies for Cultural Security of College English Education}

\section{Emphasize cultural consciousness and assistant students in establishing correct concepts}

So-called cultural consciousness refers to the circumstance that we should have certain cognition and self-knowledge toward the culture(s) that we understand and have a clear understanding of cultural origin, history, characteristics and cognition of future development toward the society that we live. This cultural consciousness is also served as rational examination of the mankind toward themselves as well as a kind of self-awareness of the mankind. This cultural consciousness is featured by diversification, multiple-dimension, comprehensiveness, conscientiousness and others. In short, it is a complete value structure of the cultural system. A scholar ever pointed out that cultural consciousness was not only knowledge of people living in certain culture on such culture and full cognition of the origin, history, features and future of such culture but also a kind of rational examination of the mankind toward their destiny and a complete cultural value structure of subject consciousness ego, behavioral conscientiousness, global horizon, content comprehensiveness, diversified expressions, multi-dimensional targets and system completeness. In the development course of the whole cultural system, we should not regress or completely optimize. College foreign language teaching itself is a kind of cultural nature of universal value integrated with modern requirements. In the process of foreign language education, foreign language education workers 
should regard cultural consciousness as starting point of their works as well as core objective of educational activities. As initiators and transmitters of foreign language knowledge, foreign language education workers also need to become practitioners of cultural consciousness. Therefore, foreign language education workers should maintain the sense of mission for culture and stand on the leading edge of culture to maintain cultural consciousness. In China's college foreign language education, the issue of the implementation of teachers' foreign language security consciousness exists. Under the influence of some western cultures, China's foreign language education is seriously influenced and obviously restrained by western normal forms. Western culture always takes seeking for objective laws of objects as its educational mission. Relatively speaking, it will result in some knowledge deviating from national culture. In the development process of education activities, some quantitative and qualitative scientism methods are used to treat foreign language education. The objectivism knowledge-based view is even used to distinguish culture. It is easy for such value to cause certain misleading for people. In the development process of foreign language education, we should use for reference the essence of western culture. However, cultural consciousness must be maintained for foreign language education. With the development of opening up in China, practicability and humanity of foreign language become more and more important, covering the use of many levels such as politics, science and technology, history, society, humanity and economy. We should also reinforce our cognition of culture, history and ethics while improving our foreign language proficiency. Moreover, we should also help college students to establish correct view of life, world view and value. In the development process of foreign language education, relevant workers should intensify the cultivation of college students' international consciousness, professional ethics, national consciousness and other contents, so as to promote the improvement to college students' moral education.

\section{Strengthen the cultivation of national spirit and establish inner cultural self-esteem}

Language is served as the basis for tradition and national spirit of a country and a nation. In a manner of speaking, language education is the essence of a country and a nation. Certain conflicts will be generated during exchanges between national tradition and spirit and other different cultures. A recreation process can be formed through integration and reference with foreign cultures. Foreign language education 
is just such a collision process. Therefore, the best educational basis for cultural security is to establish cultural self-esteem in the heart. We should establish a diversified cultural education concept with strong coordination, effectively organize international cultural exchange, research and analyze such exchange and use for reference the essence of multiple cultures. Furthermore, we should also continuously compare with other foreign cultures and establish our cultural self-confidence through the comparison with multiple cultures. For some cultural hegemony, we should dare to make a statement, establish the cultural subject of our foreign language education, and maintain the dominant role of China through this educational subject. In addition, we should strengthen publicity and promotion of excellent traditional culture of Chinese nation, inherit the civilization of China for five thousand years, help students to overcome the influence of cultural nihilism and attach importance to the cultivation of Chinese national spirit, positively develop discussion meetings and seek for culture brands with Chinese style. Besides, we should edify college students with the charm of Chinese culture, letting them really establish cultural self-esteem in the heart. We should also participate into cultural exchange with positive, open and persistent attitudes and obtain higher cultural status for that.

\section{Be brave to make cultural innovation and break old-fashioned thoughts of national culture}

The ultimate aim of foreign language education is to maintain cultural security through cultural innovation. For cultural innovation, it is necessary for us to have certain advanced concepts. Therefore, we should be brave to bring forth new ideas, break old-fashioned thoughts in national culture and effectively combine with innovative cultural thoughts. Besides, we should also intensify independent consciousness, consciousness of efficiency and sense of competition of college students, cultivate innovation ability of college students and be brave to challenge old-fashioned traditional culture, so as to effectively promote the improvement to cultural advancement. Educational institutions should make innovation to educational method, concept, structure and content, effectively give play to the cultural security innovative function of foreign language education, recreate cultural contents through cultural innovation, and embody the epochal character of knowledge contents through curriculum provision, especially in culture introduction. We should properly increase traditional culture, and utilize different cultures for 
promotion and complementation. In the learning process, students should cultivate their consciousness of diversified culture by learning about world culture. In the development process of foreign language education, we should also introduce knowledge about Chinese culture into education, and enhance the consciousness of students to spread local culture and national spirit. This is also an effective means used to cultivate the students' consciousness of state responsibility. In the teaching process, foreign language teachers should initiate foreign language knowledge, and deepen cultural accomplishment of students. However, artistic appreciation of foreign language teachers is also of great importance. Foreign language teachers should make a complete quality training plan, so as to meet relevant needs of educational work. Cultural knowledge can be effectively arranged through the improvement to artistic appreciation of foreign language teachers. Moreover, various levels of knowledge hierarchy can be specified, so as to perform flexible foreign language education according to different development needs of different students. Moreover, foreign language teachers should also make continuous innovations to educational form, and create positive and healthy educational form by combining traditions and development needs of times. For instance, China effectively carried forward its national culture through Confucius Institute and formed a new wave of Chinese fever in the world. This also indicates that Chinese traditional culture is of certain modern value. From another perspective, it also symbolizes the sharp rise of Chinese national culture, letting more foreigners long for understanding Chinese national culture and continuously participate into experience of Chinese national culture. It effectively improves the global status of China.

\section{Enhance the consciousness of mother language and promote the improvement of foreign language level and proficiency}

With the deepening of opening to the outside world and under the background of globalization, many people's consciousness of native language was weakened. To be specific, modern people lay much emphasis on foreign language rather than native language. In the current education system, China offered abundant foreign language courses in the elementary education stage, far exceeding the requirements of the teaching program. The foreign language courses are completely equivalent to Chinese courses. In the college stage, contents of foreign language teaching are much more than contents of Chinese learning. Such education system lets some 
students generate certain slight attitudes for native language. Fundamentally, ignorance of native language education will influence students' foreign language level and competence to a large extent, for instance, translation competence. Thus, we need to cultivate professional foreign language talents, reinforce their consciousness of mother language, feel national culture through learning of mother language and promote the improvement to foreign language level and competence.

\section{Conclusion}

It is necessary for foreign language education to begin with the cultivation of cultural consciousness, cultivate students to have a better understanding of their culture, and help students to form cultural view and culture consciousness with their features. Only in this way, China's foreign language education can become a tower of strength to carry forward Chinese traditional culture.

\section{References:}

[1] Cheng Xiaotang, Enlightenment of Linguistic Theory on Formulation of China's Foreign Language Education Policies [J], Foreign Language Teaching and Research, 2012, (02);

[2] Tong Xiaomei, Strategies for Foreign Language Education under Globalization [N], Guangming Daily, 2010, 05, 12;

[3] Zhou Feifang, Survey on Deficiency of Chinese Folk Culture under English Popularization [J], Journal of Xinyu College, 2012, (01);

[4] Dai Manchun, Strategies for American Foreign Language Education with the Orientation of National Security [J], Foreign Language Teaching and Research, 2012, (04). 